\title{
Utilização de microssatélites e RAPD na caracterização molecular de acessos de Paspalum urvillei Steudel
}

\section{Joaquim Taizo Sawasato ${ }^{1}$, Miguel Dall'Agnol${ }^{2}$, Daniele Priscila da Conceição ${ }^{3}$, Vilmar Tafernaberri Junior ${ }^{4}$, Gabriel Baracy Klafke ${ }^{4}$}

\footnotetext{
${ }^{1}$ Mestrando do PPG - Zootecnia/UFRGS. Bolsista do CNPq.

2 Departamento de Plantas Forrageiras e Agrometeorologia, Faculdade de Agronomia/UFRGS, Av. Bento Gonçalves 7712, CEP: 91501-970, Porto Alegre, RS, Brasil. Bolsista do CNPq.

${ }^{3}$ Bióloga - Estagiária no Laboratório de Análises Genéticas, Departamento de Plantas Forrageiras e Agrometeorologia, Faculdade de Agronomia/UFRGS.

${ }^{4}$ Curso Superior de Tecnologia em Agropecuária: Sistemas de Produção - UERGS, Estagiário no Laboratório de Análises Genéticas, Departamento de Plantas Forrageiras e Agrometeorologia, Faculdade de Agronomia/UFRGS.
}

RESUMO - Este estudo foi realizado com o objetivo de verificar a diversidade genética na coleção de acessos de $P$. urvillei do Departamento de Plantas Forrageiras e Agrometeorologia (DPFA) da Faculdade de Agronomia (UFRG) visando sua utilização em futuros trabalhos de seleção. Foram avaliados 64 acessos provenientes do Rio Grande do Sul, 1 de Xanxerê, Santa Catarina, três de Curitiba, Paraná, e 1 da Argentina. A diversidade genética foi analisada por meio de marcadores do tipo RAPD e SSR Utilizaram-se dez primers para marcadores RAPD, o que possibilitou obter 56 bandas polimórficas e 11 grupos no dendrograma com similaridade média de 0,70. Na técnica de SSR, foram utilizados sete primers e obtidas 28 bandas polimórficas, formando sete grupos no dendrograma com similaridade média de 0,66. Ambos os marcadores foram eficientes para o agrupamento de acessos coletados. O uso de maior número de primers para gerar mais bandas polimórficas foi necessário para obtenção de fingerprints genômicos dos indivíduos similares. Os dendrogramas gerados neste estudo dão subsídios para futuros cruzamentos de gerações parentais contrastantes ou similares no melhoramento de Paspalum urvillei.

Palavras-chave: diversidade genética, marcadores moleculares, melhoramento de plantas, Paspalum urvillei

\section{Genetic diversity among accesses of Paspalum urvillei Steudel estimated by microssatelites and RAPD markers}

\begin{abstract}
The aim of this study was to estimate the genetic diversity among accesses of $P$. urvillei of Departamento de Plantas Forrageiras e Agrometeorologia (DPFA) of the College of Agronomy - UFRGS and to evaluate their use in selection programs. Sixty four accesses from different cities of the Southern Region of Brazil (Rio Grande do Sul, Santa Catarina and Parana States) and from Argentine were analyzed by RAPD and SSR molecular markers. Ten primers of RAPD markers were used and resulted in 56 polymorphic bands and 11 groups in a dendrogram with average similarity 0.70. Seven primers were used for the SSR technique and resulted in 28 polymorphic bands and seven groups in a dendrogram with average similarity 0.66. Both markers were efficient on grouping the accesses collected across the Southern region. A large number of primers was required to generate additional polymorphic bands to get genomic fingerprints of similar individuals. The dendrograms obtained from this study provided significant information for designing crossing strategies of parental generations in breeding programs of $P$. urvillei.
\end{abstract}

Key Words: genetic diversity, molecular markers, Paspalum urvillei, plant breeding

\section{Introdução}

Entre as gramíneas nativas do Brasil, o gênero Paspalum L. destaca-se pelo maior número de espécies, muitas com valor nutritivo satisfatório e com potencial para serem utilizadas como recurso forrageiro. As espécies do gênero, que se destacam pela tolerância ao frio e pela produção e qualidade de forragem, são utilizadas há algum tempo na alimentação de bovinos no Rio Grande do Sul (Prestes et al., 1976).

A maioria das espécies do gênero Paspalum é apomítica poliplóide, principalmente tetraplóide. Entretanto, muitas dessas espécies apomíticas tetraplóides têm coespecíficos sexuais, diplóides e auto-incompatíveis (Quarín 
\& Normann, 1990). Entre os 20 grupos taxonômicos estabelecidos por Barreto (1974), são importantes para a região subtropical os grupos Dilatata, Plicatula e Notata. Quatro biótipos sexuais e apomíticos do grupo Dilatata convivem nesta região: $P$. dilatatum Poiret, $P$. urvillei Steudel, $P$. pauciciliatum Parodi e $P$. dasypleurum Kuntze ex Desv. (Valls \& Pozzobon, 1987). Considera-se queP. urvilleiseja o tetraplóide sexual envolvido na origem de novos pentaplóides, em virtude de suas características de polinização - atua tanto como doadora de pólen quanto como receptora (Caponio \& Quarin, 1990).

Segundo Rosengurt (1976), Paspalum urvillei apresenta considerável produtividade e capacidade para suportar altas taxas de lotação durante a primavera e o verão.

A existência de variabilidade genética é fundamental em todo programa de melhoramento de plantas (Allard, 1971) e pode ser verificada por meio de características morfológicas e moleculares (Federizzi, 1998). A tecnologia de marcadores moleculares tem sido amplamente utilizada no melhoramento de várias culturas. Os marcadores moleculares podem ser empregados em praticamente todas as etapas do melhoramento de plantas. Segundo Ferreira \& Grattapaglia (1998), esses marcadores permitem ao pesquisador maior informação de dados, que, associados aos dados fenotípicos, complementam os resultados dos programas de melhoramento.

A caracterização molecular, além de útil para o agrupamento de genótipos, tanto para planejamento de cruzamentos quanto para seleção de genótipos promissores, pode ser utilizada como fingerprinting (impressão digital) dos cultivares desenvolvidos e recomendados incorporados ao processo de proteção. Assim, este trabalho foi realizado com o objetivo de verificar a diversidade genética entre acessos de P. urvillei da coleção do DPFA da Faculdade de Agronomia - UFRGS visando sua utilização em futuros trabalhos de seleção de materiais de interesse para a produção animal.

\section{Material e Métodos}

O experimento foi conduzido no Laboratório de Análise Genética do Departamento de Plantas Forrageiras e Agrometeorologia (DPFA) da Faculdade de Agronomia da Universidade Federal do Rio Grande do Sul (UFRGS). Foram avaliados 64 acessos (Tabela 1) provenientes de diversos municípios do estado do Rio Grande do Sul, incluindo 1 acesso de Xanxerê, de Santa Catarina, três acessos de Curitiba, Paraná, e 1 da Argentina.

O DNA foi extraído imediatamente após a coleta de um conjunto de folhas de plantas jovens mantidas em vasos
Tabela 1 - Origem e locais de coleta de acessos de Paspalum urvillei

\begin{tabular}{lc}
\hline Número do acesso & Origem \\
\hline 1 & Dom Feliciano \\
2 & Dom Feliciano \\
3 & Dom Feliciano \\
4 & Dom Feliciano \\
5 & Encruzilhada do Sul \\
6 & Encruzilhada do Sul \\
7 & Canguçu \\
8 & Canguçu \\
9 & Canguçu \\
11 & Piratini \\
13 & Santana da Boa Vista \\
14 & Santana da Boa Vista \\
15 & Santana da Boa Vista \\
16 & Santana da Boa Vista \\
17 & Cachoeira do Sul \\
18 & Caxias do Sul \\
21 & Lageado Grande \\
23 & Lageado Grande \\
25 & Cambará do Sul \\
26 & Cambará do Sul \\
27 & Jaquirana \\
28 & Bom Jesus \\
29 & Sag
\end{tabular}

São José dos Ausentes

São José dos Ausentes Bom Jesus

Campestre da Serra Ipê

Rosário do Sul

Cerro do Jarau

Xangri-lá

Xangri-lá

Xanxerê

Passo Fundo

Três de Maio Ijuí

Santa Rosa

Cruz Alta

Rosário do Sul Bagé

Eldorado do Sul

André da Rocha

Pinheiro Machado

Pinheiro Machado

Santana do Livramento

Santana do Livramento

Santana do Livramento Quarai Cristal

Hulha Negra Alegrete

Dom Pedrito Bagé

São Gabriel

São Gabriel

Porto Lucena

Curitiba

Curitiba

Curitiba

Argentina

Picada Café

Picada Café

Picada Café

Cerro Grande do Sul Ijuí
Local de coleta

Serra do Sudeste

Serra do Sudeste

Serra do Sudeste

Serra do Sudeste

Serra do Sudeste

Serra do Sudeste

Serra do Sudeste

Serra do Sudeste

Serra do Sudeste

Serra do Sudeste

Serra do Sudeste

Serra do Sudeste

Serra do Sudeste

Serra do Sudeste

Depressão Central

Serra do Nordeste

Campos de Cima da Serra

Campos de Cima da Serra

Campos de Cima da Serra

Campos de Cima da Serra

Campos de Cima da Serra

Campos de Cima da Serra

Campos de Cima da Serra

Campos de Cima da Serra

Campos de Cima da Serra

Campos de Cima da Serra

Campos de Cima da Serra Campanha

Campanha

Litoral Norte

Santa Catarina

Planalto Médio

Vale do Alto Uruguai

Planalto Médio

Vale do Alto Uruguai

Planalto Médio

Campanha

Campanha

Depressão Central

Serra do Nordeste

Serra do Sudeste

Serra do Sudeste

Campanha

Campanha

Campanha

Campanha

Serra do Sudeste

Campanha

Campanha

Campanha

Campanha

Campanha

Campanha

Vale do Alto Uruguai

Paraná

Paraná

Paraná

Argentina

Serra do Nordeste

Serra do Nordeste

Serra do Nordeste

Serra do Sudeste

Planalto Médio
Litoral Norte 
com substrato comercial, de modo que cada uma das 64 plantas constituiu uma amostra. O material foi macerado com auxílio de cadinhos, pistilos e nitrogênio líquido, segundo protocolo de extração adotado por Doyle \& Doyle (1987). A quantificação de DNA foi realizada utilizando-se espectrofotômetro Qubit ${ }^{\mathrm{TM}}$ fluorometer, da Invitrogen ${ }^{\circledR}$. A concentração das soluções de trabalho de DNA foi de $3 \mathrm{ng} / \mu \mathrm{L}$ para reações de PCR para o RAPD e de $5 \mathrm{ng} / \mu \mathrm{L}$ para as reações de PCR para o SSR.

A reação da polimerase em cadeia (PCR) para o marcador de polimorfismo de DNA amplificado ao acaso (RAPD) foi baseada no protocolo descrito por Ferreira \& Grattapaglia (1998), com modificações. O volume final de reação, de $20 \mu \mathrm{L}$, foi composto de $5,0 \mu \mathrm{L}$ da solução de trabalho de DNA (15 ng/ $\mu \mathrm{l}), 2,0 \mu \mathrm{L}$ de tampão PCR 10X, 0,93 $\mu \mathrm{L}$ de $\mathrm{MgCl}_{2}$ (50 mM), 1,38 $\mu \mathrm{L}$ de $10 \mathrm{mM}$ de dNTP mix contendo $2,5 \mathrm{mM}$ de cada um dos quatro nucleotídeos (dATP, dTTP, dCTP, dGTP), $4 \mu \mathrm{L}$ de primer $(5 \mathrm{ng} / \mu \mathrm{L}), 0,27 \mu \mathrm{L}$ de $T a q$ DNA polimerase $(5 \mathrm{U} / \mu \mathrm{L})$ e água MiliQR esterilizada para completar o volume. Foram utilizados oito primers da empresa Operon Technologies (Alameda, CA) (Primers: OPA1; OPA7; OPA8; OPA9; OPA18; OPB6; OPG3; OPG4) e dois primers da University of British Columbia (Vancouver, BC) (UBC3; UBC9), de acordo com trabalhos anteriormente realizados com Trifolium repens L., Trifolium pratense L., Lotus corniculatus L., Lolium multiflorum L.

As condições de amplificação de RAPD seguiram o protocolo de Casa et al. (2002), que consiste de um ciclo de 1 minuto a $93^{\circ} \mathrm{C}, 1$ minuto a $36^{\circ} \mathrm{C}$ e 2 minutos a $72^{\circ} \mathrm{C} ; 40$ ciclos de amplificação de 1 minuto a $93^{\circ} \mathrm{C}, 1$ minuto a $36^{\circ} \mathrm{C}$ e 2 minutos a $72^{\circ} \mathrm{C} ; 5$ minutos a $72^{\circ} \mathrm{C}$ e, finalmente, de temperatura constante de $4^{\circ} \mathrm{C}$ para conservação do produto da reação até a retirada das amostras do aparelho. O produto da reação foi submetido à eletroforese em gel de agarose a $1,5 \%$ com brometo de etídio $(0,4 \mu \mathrm{L} / \mathrm{mL})$ submerso em tampão TBE $1 \mathrm{X}$ a uma corrente de $100 \mathrm{~V}$ por 2 horas. Os géis foram fotografados sob luz ultraviotela e os fragmentos das amostras determinados por comparação a um padrão de $100 \mathrm{pb}$ (Invitrogen) utilizando-se o programa Kodak EDAS 290 (Electrophoresis and Analysis System). Em seguida, foi gerada uma matriz binária com auxílio do programa NTSYS pc 2.1 (Numerical Taxonomy and Multivariate Analysis System) (Rolph, 2001). A matriz de similaridade foi construída com base no índice de Jaccard e, a partir dela, foi construído um dendrograma de similaridade entre os acessos pelo módulo SAHN do NTSYS utilizando-se o método de média de distâncias (UPGMA Unweighted Pair-Group Method using un Arithmetic Average).
A reação de PCR para o SSR foi adaptada do protocolo descrito por Wang et al. (2006), com modificações. O volume final de reação, de $15 \mu \mathrm{L}$, foi composto de $3 \mu \mathrm{L}$ da solução de trabalho de DNA (15 ng/ $\mu \mathrm{L}), 1,5 \mu \mathrm{L}$ de tampão PCR $10 \mathrm{X}, 0,90 \mu \mathrm{L}$ de $\mathrm{MgCl}_{2}(50 \mathrm{mM}), 0,6 \mu \mathrm{L}$ de $10 \mathrm{mM}$ de dNTP mix contendo $2,5 \mathrm{mM}$ de cada um dos quatro nucleotídeos, 1,2 $\mu \mathrm{L}$ de primer $(100 \mathrm{ng} / \mu \mathrm{L}), 0,27 \mu \mathrm{L}$ de Taq DNA polimerase ( $5 \mathrm{U} / \mu \mathrm{l})$ e água MiliQ esterilizada para completar o volume. Utilizaram-se sete primers (Pv-1; Pv-3; Pv-53; M-15; TRSSRA01H11; TRSSRA02C03; TRSSRAXX31), de acordo com trabalhos anteriormente realizados com Lolium multiflorum L. (Kubik et al., 1999), Paspalum vaginatum Sw. (Wang et al., 2006) e Trifolium repens $\mathrm{L}$. (Kölliker et al., 2001).

As condições de amplificação de SSR seguiram o protocolo de Wang et al. (2006): desnaturação a $94^{\circ} \mathrm{C}$ por 4 minutos (primeiros dez ciclos); $94^{\circ} \mathrm{C}$ por 1 minuto; $50^{\circ} \mathrm{C}$ por 30 segundos; e $72^{\circ} \mathrm{C}$ por 40 segundos. A cada ciclo, houve aumento de $0,5^{\circ} \mathrm{C}$ na temperatura de anelamento; nos 35 ciclos posteriores, $94^{\circ} \mathrm{C}$ por 1 minuto, $45^{\circ} \mathrm{C}$ por 30 segundos $72^{\circ} \mathrm{C}$ por 40 segundos e, finalmente, extensão a $72^{\circ} \mathrm{C}$ por 10 minutos e estoque a $4^{\circ} \mathrm{C}$. O produto da reação foi submetido a eletroforese em gel de agarose a $3 \%$ com brometo de etídio, submerso em tampão TBE $1 \mathrm{X}$, a uma corrente de $120 \mathrm{~V}$ por 2 horas. Para captação da imagem das bandas do gel, utilizou-se o mesmo procedimento descrito para a técnica de RAPD. A análise dos géis de SSR resultou em uma matriz binária empregada na construção da matriz de similaridade utilizando-se o índice de Jaccard. A partir dessa matriz, foi gerado um dendrograma de similaridade entre os acessos pelo módulo SAHN do NTSYS utilizando-se o método de média de distâncias (UPGMA - Unweighted Pair-Group Method using un Arithmetic Average).

\section{Resultados e Discussão}

Dez iniciadores foram selecionados para a técnica dos marcadores do tipo RAPD. Desses 10 iniciadores, foram geradas 3 (UBC - 9) a 9 bandas (OPA - 1), resultando em 53 bandas polimórficas, as quais foram utilizadas na avaliação da diversidade genética dos 64 acessos de Paspalum urvillei. O tamanho dos fragmentos variou de 200 a 1.900 pb.

A matriz de similaridade gerada pelo Índice de Jaccard revelou variação de 0,24 a 1,0 entre os acessos e similaridade média de 0,70 , bem próximo ao obtido por Casa et al. (2002) ao analisarem a variabilidade entre biótipos sexuais e apomíticos de Paspalum dilatatum. Esses autores verificaram índices de similaridade de 0,76 entre acessos 
sexuais e apomíticos e de 0,91 entre biótipos apomíticos, comprovando altos índices de similaridade entre acessos. Os menores índices de similaridade foram observados nas comparações do acesso 23 (Lageado Grande) com o acesso 88 (Cerro Grande do Sul), com o acesso 84 (Argentina) e com o acesso 83 (Curitiba), cujos índices de similaridade foram de 0,24; 0,30; e 0,32, respectivamente. Estes baixos índices contribuíram para que o acesso 23 apresentasse a menor média de similaridade $(0,46)$ na comparação a os outros 63 acessos.

A partição da variabilidade entre populações é grande em espécies alógamas e caracteriza-se por gerar altaheterogeneidade. Cada indivíduo em populações de espécies alógamas é altamente heterozigótico e diferente dos demais. As espécies alógamas possuem maior plasticidade em relação às espécies autógamas e gradativamente otimizam sua freqüência gênica para o ambiente onde são cultivadas. Nas espécies autógamas, a variabilidade interpopulacional é maior que nas espécies alógamas, uma vez que, em virtude do seu modo de reprodução, as espécies autógamas formam populações adaptadas ao habitat, tornando populações mais distintas entre si que no caso de espécies alógamas (Borém, 2005).
Em geral, os índices de similaridade encontrados foram altos. Considerando que Paspalum urvilleié uma espécie autógama, seria esperado que populações coletadas em diferentes locais pudessem ter se diferenciado ao longo tempo e por meio desse processo diminuído a heterogeneidade e favorecido os genes para adaptação ao seu ambiente específico. No entanto, Paspalum urvillei tem grande freqüência de dispersão, pois possui sementes com estruturas anemófilas e, segundo Valls \& Pozzobon (1987), é a espécie do grupo Dilatata com maior área de ocorrência no Brasil. Essa espécie pode formar tipos morfológicos intermediários na hibridação com $P$. dilatatum Vacaria. Miz \& Souza-Chies (2006) relatam que as distâncias genéticas entre os grupos formados por P. dilatatum, P. urvillei e seus híbridos são muito pequenas. Assim, é possível que estes altos índices de similaridade estejam relacionados ao fluxo gênico entre e dentro das populações das diversas regiões. As espécies que apresentam reprodução por autogamia também podem apresentar variação nas taxas de alogamia, o que pode reforçar a possibilidade de fluxo gênico. Portanto, a fácil dispersão, aliada a escapes de autogamia em $P$. urvillei, estaria resultando em índices de similaridade mais altos que os esperados.

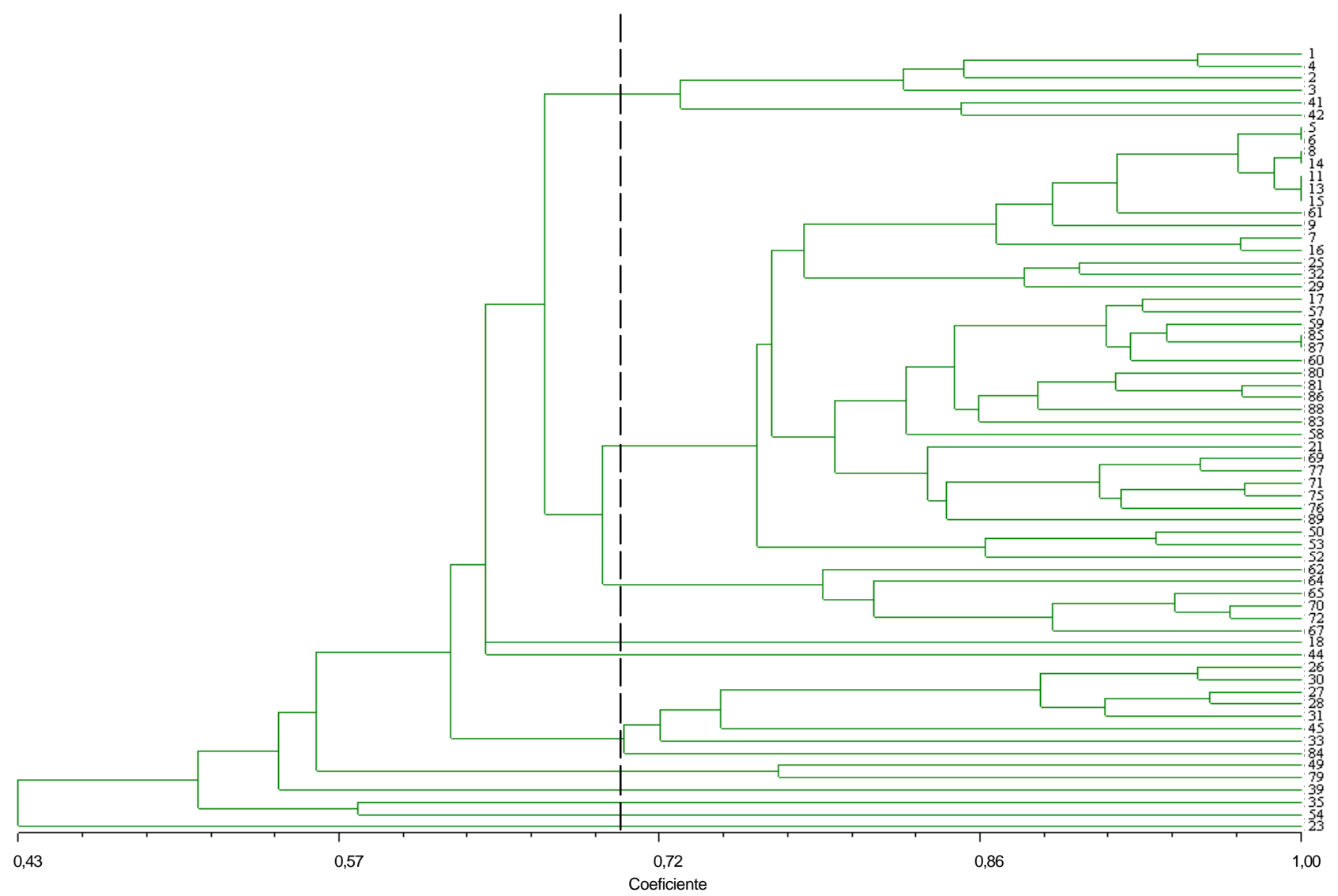

Figura 1 - Dendrograma gerado a partir da matriz de similaridade pelo Índice de Jaccard e pelo método de agrupamento UPGMA para a técnica de RAPD. 
Um bom parâmetro para verificar os padrões dos índices encontrados é a análise intrapopulacional, que permite o cálculo de valores de similaridades que podem ser comparados àqueles obtidos nas comparações entre populações. No entanto, a coleção de plantas é composta de apenas uma planta por acesso, o que impossibilita esse tipo de análise.

Observando o dendrograma e considerando como ponto de corte o valor de similaridade média de 0,70 , com os 64 acessos, formaram-se 11 grupos (Figura 1). Cinco desses grupos foram formados por apenas um indivíduo. Apenas o sétimo grupo foi formado por dois acessos, 49 e 79.

Os maiores índices de similaridade $(1,0)$ foram encontrados para acessos de mesmo município ou de municípios adjacentes. Ressalta-se que, apesar de terem sido coletadas no mesmo município, as plantas são originárias de locais diferentes, onde poderiam ter formado populações distintas na ausência de fluxo gênico. A matriz de similaridade genética indicou similaridade próxima ou superior a 0,90 entre os acessos 5 e 6 (ambos do município de Encruzilhada do Sul), 8 e 14 (Canguçu e Santana da Boa Vista), 11, 13, 14 e 15 (o primeiro de Piratini e os outros três de Santana da Boa Vista) e os acessos 85 e 87 (ambos de Picada Café).

Os acessos 1 e 4, ambos do município de Dom Feliciano, ap resentaram similaridade de 0,96. Os acessos 71 (Alegrete), 75 (Bagé), 76 e 77 (São Gabriel) apresentaram similaridade maior que 0,91 . O acesso 28 (Bom Jesus) foi bastante similar aos acessos 27 e 31, também de Bom Jesus (>0,94), assim como o acesso 27 (Jaquirana) foi similar aos acessos 28 (Bom Jesus), e 30 (São José dos Ausentes), >0,91. O acesso 59 (André da Rocha) foi similar aos acessos 85 e 87 (Picada Café), >0,93. Os acessos 50 (Ijuí) e 53 (Cruz Alta) apresentaram similaridade de 0,94 e os acessos 60 e 61, de Pinheiro Machado, 0,91. Os acessos 80, 81 e 83 (Curitiba) também apresentaram similaridade maior que 0,84. Apesar dessa clara tendência, alguns acessos coletados no mesmo município agruparam-se de forma diferente, como os acessos 25 (G2) e 26 (G6), de Cambará do Sul, 29 (G2) e 30 (G6), de São José dos Ausentes, e 21 (G2) e 23 (G11), de Lageado Grande. Os menores índices ocorreram entre acessos de diferentes regiões, como os do acesso 23 (Lageado Grande) ou o acesso 33 (Ipê), que apresentou similaridade entre 0,30 e 0,40 com os acessos 62 e 64 (Santana do Livramento), 67 (Quarai), 70 (Hulha Negra), entre outros.Considerando as exceções, há tendência de acessos de mesma região apresentarem maior similaridade entre si em comparação a acessos de outra região.

Essa análise permitiu boa discriminação dos acessos, embora não tenha possibilitado a obtenção de fingerprints genômicos de cada acesso. Aproximadamente 16\% (10 de 63) dos acessos foram iguais a algum outro indivíduo. Apesar disso, a análise foi bastante eficiente na separação de grupos distintos e no agrupamento de acessos de regiões próximas, tendo sido suficiente para subsidiar escolhas de gerações parentais para uso no melhoramento desta espécie.

Para a técnica dos marcadores do tipo SSR, foram selecionados sete iniciadores, que geraram quatro bandas, totalizando 28 bandas polimórficas. Liu et al. (1995), caracterizando a diversidade de locos em ecótipos de Paspalum vaginatum Swartz, encontraram um número maior de bandas por loco, que variou de 6 a 16 bandas, com média de 14 bandas. O tamanho dos fragmentos variou de 300 a 1.800 pares de base. A análise foi realizada com marcadores dominantes, considerando cada loco um alelo.

Neste estudo, foram utilizados primers desenhados para outras espécies, como milho (Zea mays), arroz (Oryza sativa) e sorgo (Sorghum bicolor), testados com sucesso em $P$. vaginatum por Wang et al. (2006), primers utilizados em trevo-branco (Trifolium repens) por Kölliker et al. (2001) e primers utilizados em azevém Lolium multiflorum L.) por Kubik et al. (1999). Apesar do longo tempo de evolução das espécies, algumas semelhanças dos ancestrais comuns ainda se mantiveram, o que possibilitou a utilização de primers de seqüências repetitivas.

Vários autores têm discutido (Ferreira \& Grattapaglia, 1998; Jenczewski et al., 1999) sobre a confiabilidade dos dados obtidos pela técnica do RAPD, especialmente em razão de problemas de repetibilidade. Para análises de diversidade genética de populações, essa técnica tem servido bem e gerado dados confiáveis e bastante úteis para o uso no melhoramento de plantas. Assim, realizou-se neste estudo análise da diversidade dos mesmos acessos de $P$. urvillei utilizando-se a técnica do RAPD e dos SSR a fim de comparar os dados gerados pelas duas técnicas.

Os valores de similaridade determinados pela técnica SSR variaram de 0,22 a 1,0, média de 0,66 , e foram semelhantes aos encontrados com RAPD (0,70). Esses resultados estão de acordo com os obtidos por Casa et al. (2002), que analisaram a variabilidade entre biótipos sexuais e apomíticos de $P$. dilatatum e verificaram índices de similaridade de 0,76 entre acessos sexuais.

O menor índice de similaridade $(0,22)$ foi encontrado entre os acessos 3 (Dom Feliciano) e 39 (Cerro do Jarau). Os menores valores de similaridade média na comparação de um acesso aos demais foram 0,47 para o acesso 33 de Ipê, 0,51 para o acesso 39 Cerro do Jarau e 0,52 para o acesso 67 de Quaraí. 


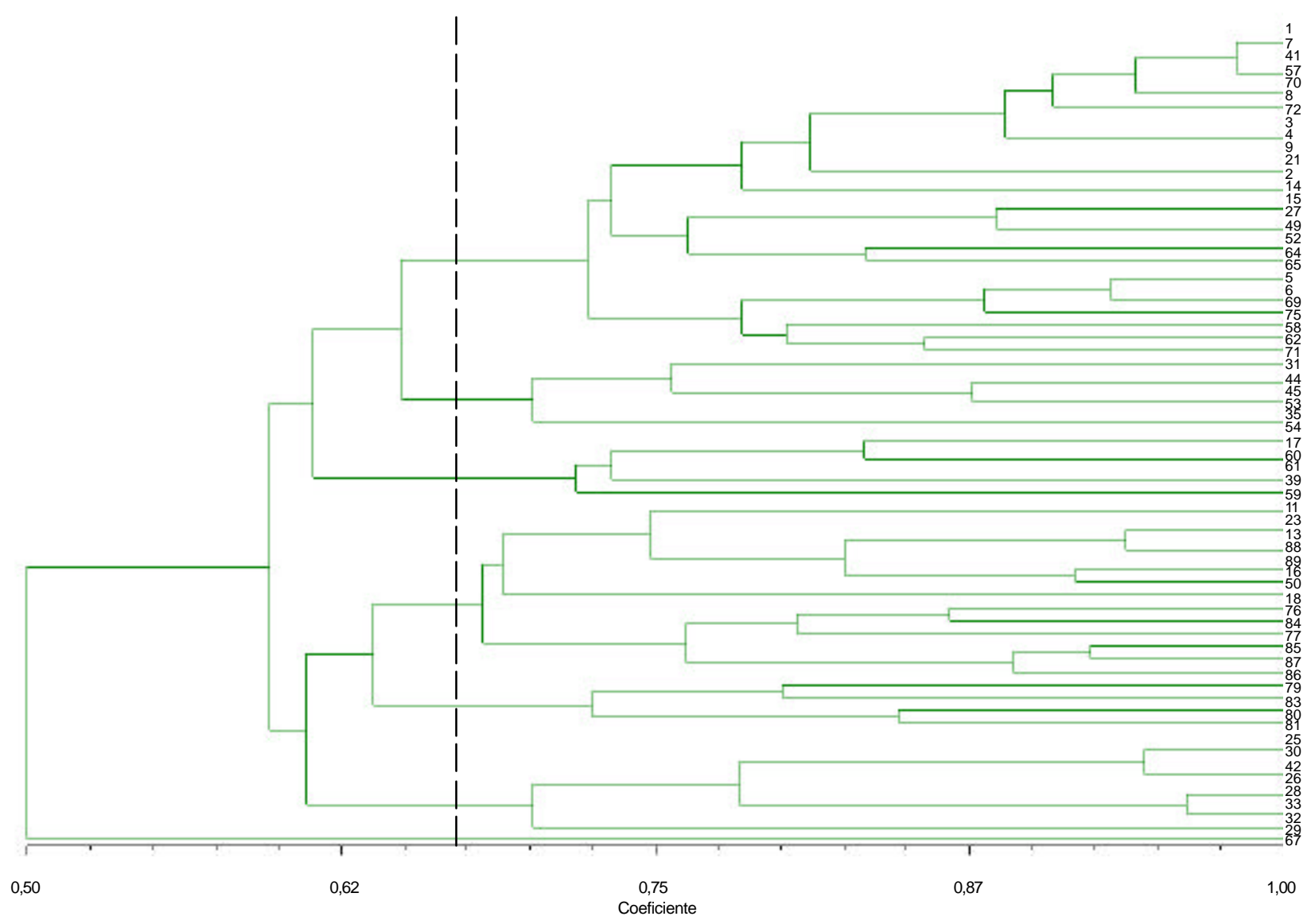

Figura 2 - Dendrograma gerado a partir da matriz de similaridade pelo Índice de Jaccard e pelo método de agrupamento UPGMA para a técnica de SSR.

A partir da matriz de similaridade obtida pelo Índice de Jaccard, foi gerado um dendrograma (Figura 2). Considerando como ponto de corte a similaridade média de 0,66 , foram encontrados sete grupos. O número de grupos obtidos no RAPD (11 grupos) foi maior em comparação ao dos marcadores SSR (sete grupos). Considerando que, com marcadores RAPD, 5 dos 11 grupos foram compostos de apenas um indivíduo, colocados entre os grupos maiores, e que, com SSR, um dos sete grupos também foi composto de apenas um indivíduo, nota-se semelhança na formação de seis grupos preponderantes entre os acessos.

Os maiores índices de similaridade encontrados foram de 1,0. Na análise realizada com SSR, o número de similaridades com índice 1,0 foi bem maior que naquela feita com RAPD. O acesso 1 (Dom Feliciano) teve similaridade acima de 0,90 com quase todos os acessos de sua região de coleta, exceto com os acessos 60 e 61 (Pinheiro Machado), 11 (Piratini) e 13 (Santana da Boa Vista). Além disso, os acessos 7 de Canguçu e 41 de Xangri-lá, 3 e 4 de Dom Feliciano e 9 de Canguçu e 21 de Lageado Grande apresentaram similaridade de 1,0. Esses valores de similaridade encontrados com o marcador SSR comprovam que os acessos de Dom Feliciano têm grande similaridade com alguns de Canguçu, pois os municípios são próximos.

Os acessos 5 e 6 (Encruzilhada do Sul), 7 e 8 (Canguçu), 14 e 15 (Santana da Boa Vista), 60 e 61 (Pinheiro Machado) apresentaram similaridade de 1,0 ou superior a 0,90 com o outro acesso do mesmo município, tanto no SSR como no RAPD, o que evidencia a proximidade genética dos acessos. Entretanto, os acessos 35 e 54, de Rosário do Sul, apesar de apresentarem similaridade de 1,0 no SSR, no RAPD, ficaram com 0,58 de similaridade, evidenciando que cada marcador tem particularidades que às vezes diminuem seu poder de discriminação.

Os acessos 45 (Passo Fundo) e 44 (Xanxerê) e os acessos 57 (Bagé) e 70 (Hulha Negra) apresentaram similaridade de 1,0 no SSR e de aproximadamente 0,70 no RAPD. Municípios próximos geograficamente tendem a apresentar indivíduos bem similares entre si. Entre acessos da região dos Campos de Cima da Serra, verificou-se alta similaridade. 
O acesso 29 (São José dos Ausentes) e os acessos 25 e 26 (Cambará do Sul) apresentaram similaridade alta, tanto no SSR como no RAPD, assim como os acessos 33 (Ipê) e 28 (Bom Jesus) apresentaram similaridade de 1,0 no SSR e, no RAPD, superiores a 0,62. Os índices de similaridade apresentados pelos acessos dos Campos de Cima da Serra foram bem próximos.

Assim como na análise com RAPD, no caso dos marcadores SSR, também houve discriminação de acessos de coleta do mesmo município em grupos diferentes, como os acessos 28 (G6) e 31(G2), de Bom Jesus, 41 (G1) e 42 (G6), de Xangri-lá, e 21 (G1) e 23 (G4), de Lageado Grande. Os acessos 21 e 23 já haviam sido discriminados em diferentes grupos com o marcador RAPD, assim como com o SSR, e apresentaram baixa similaridade.

$\mathrm{Na}$ análise da similaridade entre os acessos de cada região, apesar do maior número de acessos com similaridade 1,0, na análise com SSR, a maior média foi obtida nas análises com RAPD. Os índices de similaridade variaram de 0,67 (acessos do Vale do Alto Uruguai) a 0,90 (acessos de Curitiba) no RAPD, com média geral de 0,81 . Para SSR, as similaridades dentro das regiões variaram de 0,60 , entre os acessos do Litoral Norte, a 0,80 (acessos do Vale do Alto Uruguai) e a média geral foi de 0,72. De modo geral, os acessos de Curitiba apresentaram similaridade alta nos dois marcadores, assim como os da Depressão Central e do Planalto Médio apresentaram média de similaridade próximas à média geral, com 0,83 e 0,84 , respectivamente, no RAPD e 0,73 e 0,72, respectivamente no SSR. Os acessos da Campanha apresentaram similaridade inferior à média geral, de 0,75 no RAPD e 0,67 no SSR. Os acessos dos Campos de Cima da Serra e do Vale do Alto Uruguai apresentaram similaridade média inferior no RAPD $(0,75$ e 0,67 , respectivamente) e superior no SSR (0,75 e 0,80, respectivamente). Os acessos da Serra do Nordeste e do Litoral Norte, porém, foram superiores à média geral no RAPD, com 0,86 e 0,85, respectivamente, e inferiores à média geral no $\mathrm{SSR}$, com 0,71 e 0,60 , respectivamente. Os valores de similaridades por região comprovaram que, apesar do agrupamento da maioria dos acessos por região, os valores estimados diferem em cada técnica, de acordo com o marcador utilizado.

A técnica de SSR promoveu discriminação satisfatória dos acessos, permitindo a construção de agrupamento evidente dos indivíduos por região de coleta. Muitos acessos apresentaram similaridade de 1,0, o que impediu aobtenção de fingerprints genômicos de cada acesso, como no caso da análise com marcadores RAPD. Do mesmo modo que no RAPD, o uso de maior número de bandas polimórficas poderia aumentar o poder de discriminação e diferenciar os acessos individualmente. Ambas as técnicas, RAPD e SSR, indicaram satisfatória definição de grupos e mostraram-se como ferramenta útil no melhoramento de $P$. urville $i$, agrupando acessos similares e apresentando os acessos mais contrastantes.

O coeficiente de correlação encontrado foi de 0,18 e indica baixa correlação entre os grupos formados nas técnicas. Sun et al. (2004), usando esses mesmos marcadores para verificar a diversidade genética em híbridos de milho, verificaram correlação de 0,34 entre as matrizes geradas por ambos os marcadores. Raina et al. (2001) verificaram alta correlação $(0,92)$ entre matrizes geradas por dados de marcadores do tipo RAPD e SSR em cultivares e espécies selvagens de Arachis sp.

A compilação dos dados das duas técnicas totalizou 17 iniciadores e 81 bandas polimórficas. Houve formação de 11 grupos (Figura 3), porém, desses grupos, nove foram compostos por um ou dois acessos. A similaridade média calculada foi de 0,69. A menor similaridade encontrada foi de 0,34 entre os acessos 33 (Ipê) e 79 (Porto Lucena), enquanto a maior similaridade foi de 1,0 entre os acessos 5 e 6, ambos de Encruzilhada do Sul, e entre os acessos 14 e 15 de Santana da Boa Vista. O primeiro grupo foi composto dos acessos de duas regiões adjacentes da metade sul do estado (Serra do Sudeste e Campanha), dos dois acessos da região da Depressão Central (17, de Cachoeira do Sul, e 58, de Eldorado do Sul), dos quatro acessos do Planalto Médio (45, de Passo Fundo, 50 e 89, de Ijuí, e 53, de Cruz Alta), dos três acessos de Curitiba (80, 81 e 83), dos quatro acessos da Serra do Nordeste (59, de André da Rocha, e 85, 86 e 87, de Picada Café), de um acesso do Vale do Alto Uruguai (52, de Santa Rosa), um acesso de Campos de Cima da Serra (21, de Lageado Grande) e um acesso do Litoral Norte (41, de Xangri-lá).

O segundo grupo foi composto de quase todos os acessos da região de Campos de Cima da Serra (25 e 26, de Cambará do Sul, 27, de Jaquirana, 28 e 31, de Bom Jesus, 29 e 30, de São José dos Ausentes, 32, de Campestre da Serra). As exceções foram os acessos 21 (primeiro grupo) e 23 (décimo primeiro grupo), de Lageado Grande, e o acesso 33 (terceiro grupo). O acesso 84, da Argentina, foi incluído neste segundo grupo.

Da região da Campanha, as exceções ao agrupamento regional foram os acessos 67 (Quarai), sétimo grupo, 39 (Cerro do Jarau), nono grupo, e 35 e 54 (Rosário do Sul), décimo grupo. Da região da Serra do Nordeste, o acesso 18 de Caxias do Sul ficou isolado no quinto grupo. Da região do Vale do Alto Uruguai, os acessos 49 (Três de Maio) e 79 (Porto Lucena) formaram o sexto grupo. O acesso 42 (Xangri-lá) foi isolado do acesso 41, do mesmo município, e ficou no oitavo grupo. O acesso 44 (Xanxerê) ficou isolado no quarto grupo. 


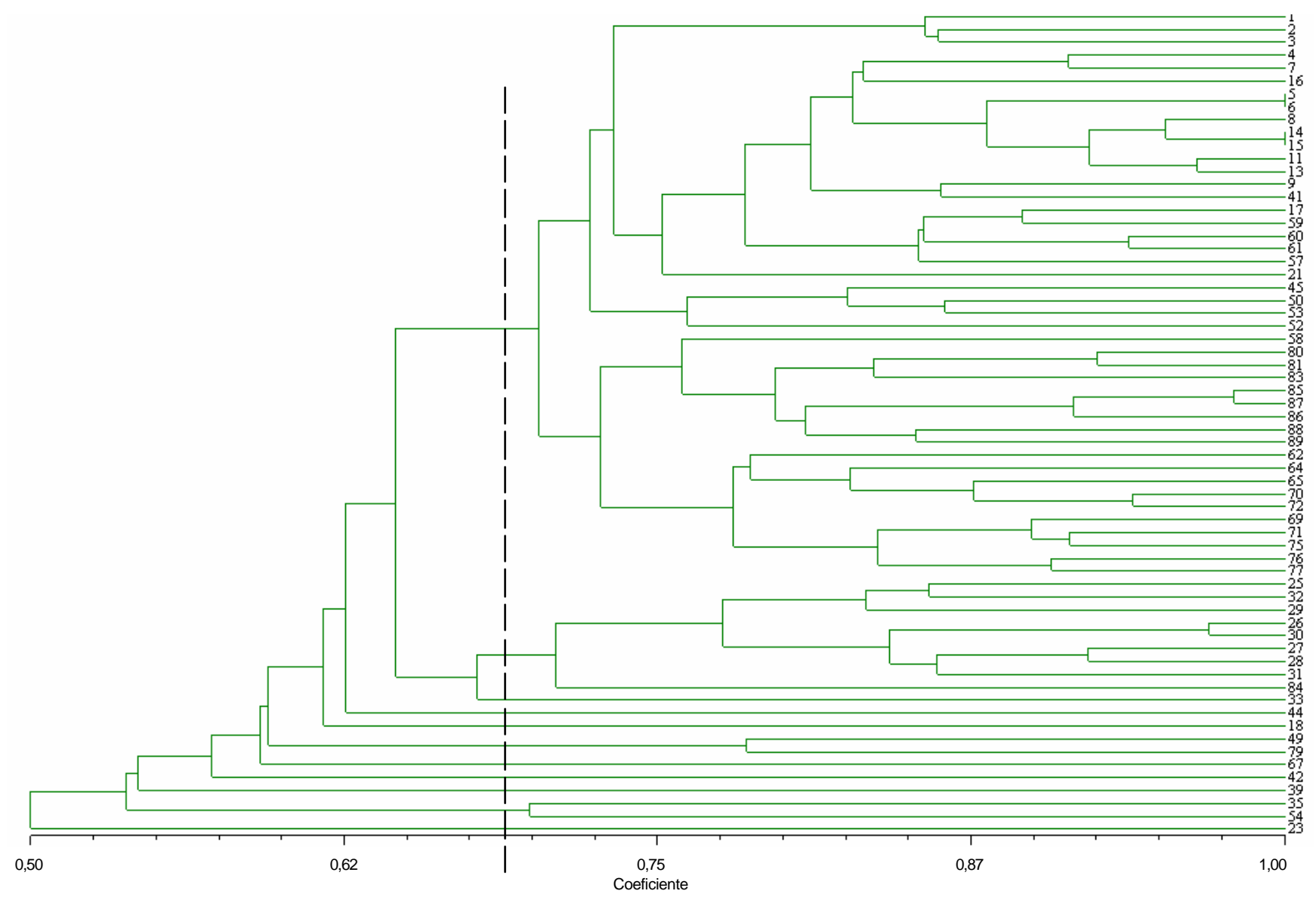

Figura 3 - Dendrograma gerado a partir da matriz de similaridade pelo Índice de Jaccard e pelo método de agrupamento UPGMA para a análise conjunta dos dados gerados pelas técnicas de RAPD e SSR.

Os acessos 5 e 6 (Encruzilhada do Sul), 14 e 15 (Santana da Boa Vista), 7 e 8 (Canguçu), 60 e 61 (Pinheiro Machado), 76 e 77 (São Gabriel), 85, 86 e 87 (Picada Café) apresentaram similaridade de 1,0 ou acima de 0,90 com o outro acesso do mesmo município. Os outros acessos coletados em mesmo município tiveram em geral similaridades acima da média em alguns casos, próxima a 0,90, como entre os acessos 80 , 81 e 83 (Curitiba). Os acessos 21 e 23 (Lageado Grande) apresentaram similaridade inferior à média, próxima a 0,61 , e os acessos 35 e 54 (Rosário do Sul) apresentaram similaridade próxima à média de 0,69 , confirmando que, apesar do mesmo município de origem, nem sempre os acessos são similares.

A análise das similaridades entre os acessos dentro de cada região indicou variações de 0,70 entre os acessos do Vale do Alto Uruguai a 0,86 entre os acessos de Curitiba, cuja média geral foi intermediária $(0,78)$ às encontradas nas análises independentes de $\operatorname{RAPD}(0,81)$ e $\operatorname{SSR}(0,72)$. As médias por região foram inferiores à média geral somente entre os acessos da Campanha $(0,73)$, dos Campos de Cima da Serra $(0,73)$ e do Vale do Alto Uruguai $(0,70)$. Entre os acessos da Depressão Central $(0,79)$, do Planalto Médio $(0,79)$ e do Litoral Norte $(0,80)$, as médias de similaridade regional foram bem próximas à média geral. Entre os acessos da Serra do Sudeste $(0,81)$, da Serra do Nordeste $(0,83)$ e de Curitiba $(0,86)$, a média foi superior à média geral. Essa mesma tendência foi observada na análise das similaridades por região no RAPD.

A tendência de agrupamento no dendrograma por regiões foi acentuada na análise conjunta dos dados das duas técnicas. O número de similaridade igual a 1,0 restringiu-se aos acessos 5 e 6 (Encruzilhada do Sul) e 14 e 15 (Santana da Boa Vista). A análise conjunta dos dados das duas técnicas é uma alternativa para a observação da similaridade ou dissimilaridade entre uma técnica e outra. Os dendrogramas gerados por este estudo dão subsídio para futuros trabalhos de seleção e melhoramento genético da espécie, pois possibilita a escolha de parentais contrastantes. 


\section{Conclusões}

As técnicas de RAPD e SSR são eficientes no agrupamento de acessos de regióes do sul do Brasil e revelam a diversidade genética entre acessos de Paspalum urvillei.

\section{Literatura Citada}

ALLARD, R.W. Princípios do melhoramento genético de plantas. Rio de Janeiro: USAID, 1971. 381p.

BARRETO, I.L. O gênero Paspalum (Gramineae) no Rio Grande do Sul. Porto Alegre: Universidade Federal do Rio Grande do Sul, 1974. 258p. Tese (Livre Docência em Fitotecnia) - Universidade Federal do Rio Grande do Sul, 1974.

BORÉM, A.; MIRANDA, G.V. Melhoramento de plantas. 4.ed. Viçosa, MG: Universidade Federal de Viçosa, 2005. 525p.

CAPONIO, I.; QUARIN, C.L. Intra and interespecific hybridization between dallisgrass and vaseygrass. Crop Science, v.30, p.362$364,1990$.

CASA, A.M.; MITCHEL, S.E.; LOPES, C.R. et al. RAPD Analysis reveals genetic variability among sexual and apomitic Paspalum dilatatum Poiret biotypes. The Journal of Heredity, v.93, n.4, p.300-302, 2002.

DOYLE J.D.; DOYLE J.L. A rapid DNA isolation procedure for small quantities of fresh leaf tissue.Phytochemical Bulletin, v19, p.11-15, 1987.

FEDERIZZI, L.C. Estrutura de um programa de melhoramento de plantas e possíveis aplicações de marcadores moleculares: visão o melhorista. In: MILACH, S.C.K. (Ed.) Marcadores moleculares em plantas. Porto Alegre: Universidade Federal do Rio Grande do Sul, 1998. p.3-15.

FERREIRA, M.E.; GRATTAPAGLIA, D. Introdução ao uso de marcadores moleculares em análise genética. Brasília: EMBRAPA-CENARGEN, 1998. 220p.

JENCZEWSKI, E.; PROSPERI, J.M.; RONFORT, J. Differentiation between natural and cultivated populations of Medicago sativa (Leguminosae) from Spain: analysis with random amplified polymorphic DNA (RAPD) markers and comparison to allozymes. Molecular Ecology, v.8, p.1317$1330,1999$.

KÖLLIKER, R.; JONES, E.S.; DRAYTON, M.C. et al. Development and characterization of simple sequence repeat (SSR) markers for white clover (Trifolium repens L.). Theoretical Applied Genetics, v.102, p.416-424, 2001.

KUBIK, C.; MEYER, W.A.; GAUT, B.S. Assessing the abundance and polymorfhism of simple sequence repeats in perennial ryegrass. Crop Science, v.39, p.1136-1141, 1999.

LIU, W.-Z.; JARRET, R.L.; KRESOVICH, L. et al. Characterization and analysis of simple sequence repeat (SSR) loci in seashore paspalum (Paspalum vaginatum Swartz). Theoretical and Applied Genetic, v.91, p.47-52, 1995.

MIZ, R.B.; SOUZA-CHIES, T.T. Genetic relationships and variation among biotypes of dallisgrass (Paspalum dilatatum Poir.) and related species using random apmplified polymorphic DNA markers. Genetic Resources and Crop Evolution, v.53, p.541-552, 2006.

PRESTES, P.J.Q.; FREITAS, E.A.G.; BARRETO, I.L. Hábito vegetativo e variação estacional do valor nutritivo das principais gramíneas da pastagem nativa do Rio Grande do Sul. Anuário Técnico do Instituto de Pesquisas Zootécnicas "Francisco Osório", v.3, p.516-531, 1976.

QUARÍN, C.L.; NORMANN, G.A. Interspecifc hibryds between five Paspalum species. Botanical Gazette, v.151, p.366-369, 1990.

RAINA, S.N.; KOJIMA, T.; OGIHARA, Y. et al. RAPD and ISSR fingerprints as useful genetic markers for analisys of genetic diversity, varietal identification, and phylogenetic relationship in peanut (Arachis hypogeae) cultivars and wild species. Genome, v.44, p.763-772, 2001.

ROHLF F.J. NTSYS-pc: numerical taxonomy and multivariate analysis system (Version 2.1). New Cork: Exeter Publishing Ltda, 2001. (CD-ROM).

ROSENGURT, B. Tablas de comportamiento de las especies de plantas de campos naturales en el Uruguay. Montevideo: Dirección General de Extensión Universitaria/División Publicaciones y ediciones, 1976. 86p.

SUN, G.L.; WILLIAM, M.; LIU, J. et al. Microsatellite and RAPD polymorphisms in Ontario corn hybrids are related to the commercial sources and maturity ratings. Molecular Breeding, v.7, n.1, p.13-24, 2004.

VALLS, J.F.M.; POZZOBON, M.T. Variação apresentada pelos principais grupos taxonômicos de Paspalum com interesse forrageiro no Brasil. In: ENCONTRO INTERNACIONAL SOBRE MELHORAMENTO DE PASPALUM, 1987, Nova Odessa. Anais... Nova Odessa: SAPF/IZ, 1987. p.15-21.

WANG, M.L.; CHEN, Z.B.; BARKLEY, N.A. et al. Characterization of seashore paspalum (Paspalum vaginatum Swartz) germplasm by transferred SSRs from wheat, maize and sorghum. Genetic Resources and Crop Evolution, v.53, p.779-791, 2006. 